\title{
Durability of mitral valve repair for degenerative mitral regurgitation: is it gold all that glitters?
}

\author{
Antonio M. Calafiore ${ }^{1}$, Antonio Totaro ${ }^{1}$, Massimiliano Foschi ${ }^{2}$, Michele Di Mauro $^{3}$ \\ ${ }^{1}$ Department of Cardiac Surgery and Cardiology, Pope John Paul II Foundation, Campobasso, Italy; ${ }^{2}$ Department of Heart Disease, SS Annunziata \\ Hospital, Chieti, Italy; ${ }^{3}$ Cardiac Surgery and Cardiology, API Madonna del Ponte, Lanciano, Italy \\ Correspondence to: Antonio M. Calafiore, MD. Professor of Cardiac Surgery, Department of Cardiac Surgery, John Paul II Foundation, Campobasso, \\ Largo Agostino Gemelli, 1, 86100 Campobasso, Italy. Email: am.calafiore@gmail.com. \\ Provenance: This is an invited Editorial commissioned by Section Editor Busheng Zhang, MD, PhD (Department of Cardiac Surgery, Shanghai Chest \\ Hospital, Shanghai Jiaotong University, Shanghai, China). \\ Comment on: Lapenna E, Del Forno B, Amore L, et al. Durability at 19 Years of Quadrangular Resection with Annular Plication for Mitral \\ Regurgitation. Ann Thorac Surg 2018;106:735-41.
}

Submitted Aug 17, 2018. Accepted for publication Aug 28, 2018.

doi: 10.21037/atm.2018.08.43

View this article at: http://dx.doi.org/10.21037/atm.2018.08.43

Mitral valve (MV) repair for degenerative mitral regurgitation (MR) is achieved nowadays with a great success rate and a good survival, similar, in certain subgroups, to that of the normal population (1). The superiority of MV repair over replacement for degenerative MR has been consistently demonstrated (2). However, even if degenerative disease of the MV is a big umbrella which covers a lot of different pathologies, most of the techniques are addressed to correct the prolapse of one or both mitral leaflets, a widely diffused disease that interested cardiac surgeons since the early years. The first chapter in the huge book of $\mathrm{MVr}$ was however written by Carpentier et al. $(3,4)$, who defined the terms and put the principles which, with some modifications, are still followed by many surgeons. His vision, together with the concept of annuloplasty (5) and the advent of artificial chords (6), are the pillars on which $\mathrm{MVr}$ surgery stands. There is no doubt that nowadays high percentage of repair can be achieved in specialized centers, but it is as well true that a huge variety of techniques are used to obtain a competent valve. Most of these have only midterm results, often very good, which justify the optimistic prevision for a high long-term patency rate.

The paper from Lapenna et al. (7) reports the long term outcome of a specific technique originally described by Carpentier et al. (4) to treat the prolapsing or flail posterior leaflet, applied in 142 patients from 1997 and 1998. Survival was $92 \% \pm 2.3 \%$ at 10 years and $74 \% \pm 3.7 \%$ at 20 -year, 6 patients were reoperated on because of recurrent severe $M R$ and the cumulative incidence function of $M R \geq 2+$ with death as competing risk was $7 \% \pm 2.1 \%$ at 10 years and $17 \% \pm 3.2 \%$ at 19 years.

These superb results underline how MV repair can have a great success rate even in the long term and can change the natural history of the disease. Recent studies showed that strain for valves with organic disease is higher than for normal valves, globally and in each valve leaflet. It was postulated that reduction of strain is one of the component which affects durability of MV repair. Indeed, valve strain reduces after MVR, and it may be related to a smaller annular size, increased valve coaptation zone, a smaller exposed valve area, and the insertion of artificial chordae, each having been shown in various models to reduce strain (8). These observations provide a scientific basis to long term results after MV repair, independently from the technique used.

Results of Lapenna et al. (7) are in line with what previously reported in the literature (9-12), even if most reports deal with prolapse of one or both leaflets. The quality of the results, at least in terms of survival, is strictly related to the presence of preoperative risk factors, as atrial fibrillation or pulmonary hypertension or reduced ejection fraction. It is indubitable that better results can be achieved when patients are operated on in an early phase, without the late consequences of the disease $(13,14)$.

However, in order to improve the outcome of $\mathrm{MV}$ repair, some complications, mostly technical, and the way of preventing them, have to be analyzed, as integral part of any surgical strategy. 


\section{Mitral stenosis (MS)}

After $M V$ repair for degenerative $M V$, the valve area decreases and the gradients increase, in general not in such a way to affect the functional capacity. However, this is an aspect intrinsic to the surgical technique, and its extent is not yet well defined. Although pannus ingrowth can develop over time reducing the MV orifice, other factors, as posterior leaflet surgery and complete annuloplasty rings, have been considered among the possible causes $(15,16)$. The increase in transmitral pressures and inflow velocities, together with a change in the vortex pattern in the left ventricle (17), are indicative of functional MS of various degrees, dependent on the size of the device implanted and on the amount of tissue left inside the mitral orifice. This problem is not negligible in an era when mitral repair is proposed to asymptomatic patients, often young and active. MS can be a serious problem in the early period, reflecting the predominance of surgical techniques. It was cause of reoperation either in the operating theatre (OR) (10) or before hospital discharge (18).

It is difficult to clarify the exact prevalence of this complication. Chan et al. (15) reported 110 patients who had MV repair for MV prolapse and found a mean gradient across the valve $>3 \mathrm{mmHg}$ in 75 patients $(68 \%)$. Most of the patients with higher gradients had complete rigid ring. In a further study with the same patients, the same authors (19) used the MV area calculated with the continuity equation. They found that $20 \%$ of the patients had a $M V$ area $\leq 1.5 \mathrm{~cm}^{2}$, which was associated with worse intracardiac hemodynamics, lower exercise capacity and adverse outcomes. The $\mathrm{MV}$ area corresponded to a mean gradient of $5 \mathrm{mmHg}$. Kawamoto et al. (20) found that $8 \%$ of their patients $(51 / 602)$ had a rest mean transmitral gradient $\geq 5 \mathrm{mmHg}$ at discharge, mostly related to a smaller ring size. These patients had during the follow up increase of tricuspid regurgitation severity, of the pulmonary pressure and higher onset of atrial fibrillation than patients with lower gradients. Interestingly, even patients where the ring used was true sized can present severe MS. Doi et al. (21) found that 7 out of 20 patients who had stress echocardiography after MV repair with a semirigid ring showed peak gradients at effort $\geq 15 \mathrm{mmHg}$. The importance of pannus development was underlined by Suh et al. (22), who, in 45 patients who had a postoperative CT scan after at least 1 year from surgery, found a pannus in 29 of them (64.4\%), significant in $10(22.2 \%)$, with a prevalence in patients with Duran ring. In general, lacking prospective studies, we can speculate that $10 \%$ to $20 \%$ of the patients with a good repair re discharged with some significant mitral stenosis, which can affect the long-term outcome.

\section{Mitral regurgitation}

Residual/recurrent MR after surgical correction is a constant and varies only as percentage. A residual MR in OR grade moderate or more needs always a second pump run. When MR is mild, it was demonstrated that there is no need of further corrections, as in more than $60 \%$ of the cases it even reduces during the follow up (23). The incidence of recurrent MR moderate or more is often reported as freedom from the event and has a great variability. It can be as low as $27.2 \% \pm 8.6 \%$ at 7 years (24) or as high as $90.4 \%$ (CI: 89.3-91.4) at 10 years (11). In percentage of patients, incidence of MR moderate or more has a wide range: $25.9 \%$ after 10 years (25), $23.6 \%$ after 5 years (26), $13.3 \%$ at 13 years (27). There is general agreement that residual MR more than mild is a risk factor for MR moderate or more at follow up $(25,27,28)$ and that correction of AL prolapse has a high rate of recurrent MR moderate or more at follow up than PL prolapse. Independently from the technical difficulties and from the possibility of further chordal elongation/rupture, a specific mechanism, in an era when chordal replacement is more and more frequent, is artificial chordal rupture. First reported in 2004 (29), its real incidence is not known. In the experience of Coutinho et al. (12) it represented the $26.1 \%(6 / 23)$ of the causes of reoperation and the $1.6 \%$ of the cases where artificial chordae were implanted. Another mechanism of recurrent MR, specific of the technique, is the dehiscence of the implanted device. The mitral annular biomechanics have been extensively studied. The strain is stronger in the commissural areas and in the anterior annulus, applying systolic torsion to a flat annuloplasty ring. This is in favor of saddle shaped rings, which present superior uniform annular distribution $(30,31)$. The suture force maximums and their corresponding cyclic ranges (maximum to minimum) are greater along the anterior portion of the ring (32). As the collagen density of the anterior annulus is greater than the posterior annulus (33), the former can tolerate much higher tensile force, this would predispose to dehiscence along the posterior annulus, which is what is seen clinically, despite lower cyclic loading on posterior sutures. In other studies the posterior annulus, in particular at the intersection of the right commissural segment with the posterior segment, was found to be the weakest part of the mitral annulus (34). 
Incidence of the dehiscence of the ring/band varies in the different statistics. It represents $17 \%$ (35) to $42 \%$ (36) of the causes of reoperation, but its real incidence is not clear. In a recent series related to 475 patients operated on during 20 years ring dehiscence was the cause of reoperation in $21.6 \%$ of the cases $(5 / 23)$, representing $1.1 \%$ of the total population (12).

\section{Systolic anterior motion (SAM)}

The prevalence of SAM after MV repair remained more or less constant during the last decades, being $9.1 \%$ in 1994 (37), $8.4 \%$ in 2007 (38) and $8.1 \%$ in 2017 (39). There is general agreement that the genesis of SAM is due to the movement of the coaptation point of the leaflets toward the septum, resulting in the extension of the residual AL beyond the coaptation point. Consequently, the AL tip strays into the left ventricular outflow tract (LVOT) and, as a consequence, the ejected blood flow force moves the AL more toward the LVOT. This causes both MR and LVOT obstruction. The displacement of the coaptation between leaflets toward the septum is related to an excess of movement of the PL. SAM seems to be more frequent when a rigid ring is used (40). In most cases the solution is medical (discontinuation of inotropes, increasing the filling of the LV). In some cases a second pump run is necessary, either to improve the correction or to increase the size of the ring or to perform other maneuvers [edge to edge (39) or resection of a bulging septum (41)] or to replace the mitral valve (42). However, SAM can persist at follow up. In the experience of Brown et al. (38) after 5 years from surgery 17 patients $(9.8 \%$ of the patients who experienced SAM in OR and $0.8 \%$ of all patients who underwent MV repair) had persistent SAM with/out LVOT obstruction.

\section{Conclusions}

Long term results of MV repair for degenerative mitral regurgitation, in particular due to leaflets' prolapse, are outstanding and the paper from Lapenna et al. (7) confirms the quality of the outcome. However, we think that reporting only survival and freedom from MR gives only a partial vision of the surgical results. Thromboembolic complication are as well present in this cohort of patients, representing, in the experience of David et al. (11), the $10 \%$ of his population during a follow up of 20 years. Even if there are only sparse reports, circumflex artery injury during MV repair has been described $(43,44)$. Reporting our results must include all the possible information which can affect the quality of life of our patients. It is possible that in a relatively small number of cases, as those reported by Lapenna et al. (7), some particular complication did not occur. But, as we are proposing MV repair for prolapse of one or both MV leaflets to asymptomatic patients, we have to be aware of all the events that can affect the final results of our surgery.

\section{Acknowledgements}

None.

\section{Footnote}

Conflicts of Interest: The authors have no conflicts of interest to declare.

\section{References}

1. Tomšič A, Hiemstra YL, van Hout FMA, et al. Long-term results of mitral valve repair for severe mitral regurgitation in asymptomatic patients. J Cardiol 2018;72:473-9.

2. Lazam S, Vanoverschelde JL, Tribouilloy C, et al. TwentyYear Outcome After Mitral Repair Versus Replacement for Severe Degenerative Mitral Regurgitation: Analysis of a Large, Prospective, Multicenter, International Registry. Circulation 2017;135:410-22.

3. Carpentier A, Deloche A, Dauptain J, et al. A new reconstructive operation for correction of mitral and tricuspid insufficiency. J Thorac Cardiovasc Surg 1971;61:1-13.

4. Carpentier A. Cardiac valve surgery--the "French correction". J Thorac Cardiovasc Surg 1983;86:323-37.

5. Lillehei CW, Gott VL, Dewall RA, et al. Surgical correction of pure mitral insufficiency by annuloplasty under direct vision. J Lancet 1957;77:446-9.

6. Frater RW, Vetter HO, Zussa C, et al. Chordal replacement in mitral valve repair. Circulation 1990;82:IV125-30.

7. Lapenna E, Del Forno B, Amore L, et al. Durability at 19 Years of Quadrangular Resection with Annular Plication for Mitral Regurgitation. Ann Thorac Surg 2018;106:735-41.

8. Ben Zekry S, Freeman J, Jajoo A, et al. Effect of Mitral Valve Repair on Mitral Valve Leaflets Strain: A Pilot Study. JACC Cardiovasc Imaging 2018;11:776-7.

9. Chenot F, Montant P, Vancraeynest D, et al. Long-term clinical outcome of mitral valve repair in asymptomatic 
severe mitral regurgitation. Eur J Cardiothorac Surg 2009;36:539-45.

10. DiBardino DJ, ElBardissi AW, McClure RS, et al. Four decades of experience with mitral valve repair: analysis of differential indications, technical evolution, and longterm outcome. J Thorac Cardiovasc Surg 2010;139:76-83; discussion 83-4.

11. David TE, Armstrong S, McCrindle BW, et al. Late outcomes of mitral valve repair for mitral regurgitation due to degenerative disease. Circulation 2013;127:1485-92.

12. Coutinho GF, Correia PM, Branco C, et al. Long-term results of mitral valve surgery for degenerative anterior leaflet or bileaflet prolapse: analysis of negative factors for repair, early and late failures, and survival. Eur J Cardiothorac Surg 2016;50:66-74.

13. Meyer MA, von Segesser LK, Hurni M, et al. Long-term outcome after mitral valve repair: a risk factor analysis. Eur J Cardiothorac Surg 2007;32:301-7.

14. Zhou T, Li J, Lai H, et al. Benefits of Early Surgery on Clinical Outcomes after Degenerative Mitral Valve Repair. Ann Thorac Surg 2018;106:1063-70.

15. Chan KL, Chen SY, Chan V, et al. Functional significance of elevated mitral gradients after repair for degenerative mitral regurgitation. Circ Cardiovasc Imaging 2013;6:1041-7.

16. Mesana TG, Lam BK, Chan V, et al. Clinical evaluation of functional mitral stenosis after mitral valve repair for degenerative disease: potential affect on surgical strategy. J Thorac Cardiovasc Surg 2013;146:1418-23; discussion 23-5.

17. Witschey WR, Zhang D, Contijoch F, et al. The Influence of Mitral Annuloplasty on Left Ventricular Flow Dynamics. Ann Thorac Surg 2015;100:114-21.

18. Riegel AK, Busch R, Segal S, et al. Evaluation of transmitral pressure gradients in the intraoperative echocardiographic diagnosis of mitral stenosis after mitral valve repair. PLoS One 2011;6:e26559.

19. Chan KL, Chen SY, Mesana T, et al. Development of Mitral Stenosis After Mitral Valve Repair: Importance of Mitral Valve Area. Can J Cardiol 2017;33:1701-7.

20. Kawamoto N, Fujita T, Fukushima S, et al. Functional mitral stenosis after mitral valve repair for Type II dysfunction: determinants and impacts on long-term outcome. Eur J Cardiothorac Surg 2018;54:453-9.

21. Doi K, Yamano T, Ohira S, et al. Annuloplasty Ring Size Determines Exercise-Induced Mitral Stenosis Severity after Valve Repair. J Heart Valve Dis 2015;24:744-51.

22. Suh YJ, Chang BC, Im DJ, et al. Assessment of mitral annuloplasty ring by cardiac computed tomography:
Correlation with echocardiographic parameters and comparison between two different ring types. J Thorac Cardiovasc Surg 2015;150:1082-90.

23. Gillham M, Diprose P, Ambler J. A comparison of the degree of residual mitral regurgitation by intraoperative transoesophageal and follow-up transthoracic echocardiography following mitral valvuloplasty. Anaesth Intensive Care 2007;35:194-8.

24. Flameng $W$, Herijgers $P$, Bogaerts $K$. Recurrence of mitral valve regurgitation after mitral valve repair in degenerative valve disease. Circulation 2003;107:1609-13.

25. De Bonis M, Lapenna E, Lorusso R, et al. Very longterm results (up to 17 years) with the double-orifice mitral valve repair combined with ring annuloplasty for degenerative mitral regurgitation. J Thorac Cardiovasc Surg 2012;144:1019-24.

26. De La Zerda DJ, Cohen O, Marelli D, et al. Long-term results of mitral valve repair using autologous pericardium annuloplasty. J Heart Valve Dis 2008;17:10-5.

27. Suri RM, Clavel MA, Schaff HV, et al. Effect of Recurrent Mitral Regurgitation Following Degenerative Mitral Valve Repair: Long-Term Analysis of Competing Outcomes. J Am Coll Cardiol 2016;67:488-98.

28. Chang BC, Youn YN, Ha JW, et al. Long-term clinical results of mitral valvuloplasty using flexible and rigid rings: a prospective and randomized study. J Thorac Cardiovasc Surg 2007;133:995-1003.

29. Butany J, Collins MJ, David TE. Ruptured synthetic expanded polytetrafluoroethylene chordae tendinae. Cardiovasc Pathol 2004;13:182-4.

30. Jensen MO, Jensen H, Nielsen SL, et al. What forces act on a flat rigid mitral annuloplasty ring? J Heart Valve Dis 2008;17:267-75; discussion 75.

31. Jensen MO, Jensen H, Smerup M, et al. Saddle-shaped mitral valve annuloplasty rings experience lower forces compared with flat rings. Circulation 2008;118:S250-5.

32. Siefert AW, Pierce EL, Lee M, et al. Suture forces in undersized mitral annuloplasty: novel device and measurements. Ann Thorac Surg 2014;98:305-9.

33. Pierce EL, Siefert AW, Paul DM, et al. How Local Annular Force and Collagen Density Govern Mitral Annuloplasty Ring Dehiscence Risk. Ann Thorac Surg 2016;102:518-26.

34. Gunning GM, Murphy BP. Determination of the tensile mechanical properties of the segmented mitral valve annulus. J Biomech 2014;47:334-40.

35. Gillinov AM, Cosgrove DM, Lytle BW, et al. Reoperation for failure of mitral valve repair. J Thorac Cardiovasc Surg 
1997;113:467-73; discussion 73-5.

36. Dumont E, Gillinov AM, Blackstone EH, et al. Reoperation after mitral valve repair for degenerative disease. Ann Thorac Surg 2007;84:444-50; discussion 50.

37. Grossi EA, Steinberg BM, LeBoutillier M, 3rd, et al. Decreasing incidence of systolic anterior motion after mitral valve reconstruction. Circulation 1994;90:II195-7.

38. Brown ML, Abel MD, Click RL, et al. Systolic anterior motion after mitral valve repair: is surgical intervention necessary? J Thorac Cardiovasc Surg 2007;133:136-43.

39. Denti P, Pozzoli A, Geretto A, et al. Systolic anterior motion after mitral valve repair: a predictive computational model. Interact Cardiovasc Thorac Surg 2017;25:513-9.

40. Loulmet DF, Yaffee DW, Ursomanno PA, et al. Systolic anterior motion of the mitral valve: a 30-year perspective. J Thorac Cardiovasc Surg 2014;148:2787-93.

Cite this article as: Calafiore AM, Totaro A, Foschi M, Di Mauro M. Durability of mitral valve repair for degenerative mitral regurgitation: is it gold all that glitters? Ann Transl Med 2018;6(Suppl 1):S10. doi: 10.21037/atm.2018.08.43
41. Said SM, Schaff HV, Suri RM, et al. Bulging subaortic septum: an important risk factor for systolic anterior motion after mitral valve repair. Ann Thorac Surg 2011;91:1427-32.

42. Miura T, Eishi K, Yamachika S, et al. Systolic anterior motion after mitral valve repair: predicting factors and management. Gen Thorac Cardiovasc Surg 2011;59:737-42.

43. Calafiore AM, Iaco AL, Varone E, et al. Distortion of the proximal circumflex artery during mitral valve repair. J Card Surg 2010;25:163-5.

44. Coutinho GF, Leite F, Antunes MJ. Circumflex artery injury during mitral valve repair: Not well known, perhaps not so infrequent-lessons learned from a 6-case experience. J Thorac Cardiovasc Surg 2017;154:1613-20. 